Alfarama Journal of Basic \& Applied Sciences

Faculty of Science Port Said University

January 2021, Volume 2, Issue 1 https://ajbas.journals.ekb.eg ajbas@sci.psu.edu.eg

http://sci.psu.edu.eg/en/

DOI: $\underline{10.21608 / a j b a s .2020 .32631 .1018}$

Submitted: 21-06 -2020

Accepted: 26-07-2020

Pages: 44-50

\title{
Assessment of CA15-3 and CEA as Potential markers for Breast carcinoma prognosis in Egyptian Females.
}

\author{
F. Z. Mohammed ${ }^{1}$, Lamis Gamal ${ }^{2 *}$, Mohamed Farouk Mosa ${ }^{3}$, Mohamed Ibraheim Aref ${ }^{3}$. \\ ${ }^{1}$ Department of Biochemistry, Faculty of Science, Zagazig University, Egypt. \\ ${ }^{2}$ Department of Biochemistry, Faculty of Science, Port Said University, Egypt. \\ ${ }^{3}$ Department of Clinical Pathology, Faculty of Medicine, Al-Azhar University, Egypt.
}

*Corresponding author: dr.lamis_gamal@yahoo.com

\begin{abstract}
Background: Breast cancer is the most prevalent cancer and one of the most common mortality causes among females worldwide. Accordingly, it is a main concern of scientists and doctors. Evolving serum tumor markers helping to early diagnosis of the breast cancer and estimating important prognostic factors is then mandatory. Among them are the cancer antigen 15-3 (CA15-3) as well as the carcinoembryonic antigen (CEA). Some researchers concluded their prognostic importance while others not. Aim of the study: This research was aimed at assessing the prognostic function of CA 15-3 and CEA in the Egyptian females. Patients and methods: Research participants are $120 \mathrm{BC}$ patients and 30-year-old and BMI corresponding safety checks; the rates of CEA serum and CA 15-3 were studied and associated with the clinicopathological features of BC patients. Results: Our study showed that both markers increase significantly between healthy controls and patients with BC, and gradually increased with severity of the disease. Conclusion: our findings suggest that the levels of serum CA 15-3 and CEA were closley related to the prognosis of breast cancer, that showing a gradual increase with the severity of the disease, supporting their role as biomarkers of prognosis.
\end{abstract}

\section{Keywords}

Breast cancer, CEA, CA15-3, prognosis.

\section{Abberviation \\ CEA: Carcinoembryonic antigen. \\ CA15-3: Carcinoma antigen 15-3}

BC: breast cancer

\section{INTRODUCTION}

Breast cancer arises due to an association with an environmental (external) cause and a genetically vulnerable host [1]. Regular cells divide and stop as many times as required. They bind themselves to other cells, which live in tissue. Cells are cancerous as they lack their willingness to avoid separating, to bind themselves to other cells, to stay where they belong; And only to suffer at the right moment. Worldwide, 
breast cancer is the most prevalent malignancy among the women, as it represents $22.9 \%$ of the females malignancy [2].

A tumor marker is a substance that is secreted by normal cells and cancer cells as well. However, it shows much higher levels in case of cancer activity. It is a little invasive, relatively low cost mean of diagnosis. Yet, for being a reliable method of diagnosis, it should show high sensitivity for tumor diagnosis even in its early stages [3]. Tumor markers are also beneficial in assessment of cancer prognosis following chemotherapy and radiotherapy, so would be a base to delineate further management modification [4].

A group of closely associated glycoproteins involved in cell adhesion is identified by the carcinoembryonic antigen (CEA). CEA is normally produced during fetal development in gastrointestinal tissue but the production stops before birth. As a consequence, CEA is normally found in healthy adults' blood at very small rates (approx. 2-4 ng/mL)[5]. However, in some types of cancer, the serum levels are raised, meaning it can be used as a tumor marker in clinical tests. Serum levels in heavy smokers can also be elevated [6]. Malignant breast tumors are known to up-regulate the protein MUC1, this is the base for considering CA 15-3 protein as breast cancer biomarker. Some studies reported the utility of measuring serum CA 15-3 levels as a screening method for breast cancer among other malignant tumors. However, much false positive results were reported as in caseof smoking and benign diseases of the breast and the liver [7].

The utility of CA15-3 and CEA as biomarkers aiding in the diagnosis of recurrence cases in breast cancer is proposed. It was found by Darlix et al. that the CA 15-3 in metastatic breast cancer patients is independent prognostic factor [8].

This research was aimed at evaluating the function of serum CA15-3 and CEA as biomarkers of breast cancer in Egyptian females.

\section{PATIENTS AND METHODS}

This is study conducted from January 2019 to January 2020 at Zagazig University Hospital, Egypt. The ethical committee of Zagazig university acceptance was achieved.

The study groups:

- Group 1 (control): 30 healthy female subjects, age and BMI matching to the patient group.

- Group 2 (patients): 120 breast cancer female patients_that were, with recently pathologically proved breast cancer, of different disease stages.

Inclusion creiteria: female patients with breast cancer that where recently proved breast cancer of different disease stages

Exclustion creiteria: any patient with other malignancy (benign or malignant tumor In GIT, other chronic disease, autoimmunodisease)

\section{METHODS}

Formula: weight (lb) / [height (in)]2 x 703[9].

\section{Biochemical analysis}

serum samples of all subjects were collected and serum CA15-3 and CEA were measured according to the instructions of the manufacturer (Cell Biolabs' CEA ELISA Kit and Cell Biolabs' CA 15-3 ELISA Kit, Cell Biolabs, Inc. San Diego, USA). Information on patients is collected from the medical reports. Our patients group were divided into 4 sub groups according to different disease stages [ $\left.{ }^{\bullet}\right]$ 


\section{STATISTICAL ANALYSIS}

The software MedCal version 17.9.7 (MedCalc Software bib, Ostend, Belgium) was used for the analysis of the. Quantitave data have been represented in the form of mean and standard deviation, whereas qualitative data have been represented in the form of frequency and percent. The estimation and explanation of nottingham prognostic index (NPI) values of the patients [ $1 \cdot]$. Pearson tests were performed for serum marker association with patient clinical-pathological results.

\section{RESULTS AND DISCUSSION}

Age and BMI (table 1)

Table 1: Mean \pm SD of women age and BMI among different disease stages of studied groups.

\begin{tabular}{|l|l|l|l|l|c|}
\hline Groups & $\begin{array}{l}\text { Control } \\
\text { Group }\end{array}$ & \multicolumn{4}{|l|}{ Breast Cancer Group } \\
\cline { 2 - 6 } & $\begin{array}{l}\text { Group I } \\
\mathrm{n}=30\end{array}$ & $\begin{array}{l}\text { Group IIa } \\
\text { (Stage-I) } \\
\mathrm{n}=30\end{array}$ & $\begin{array}{c}\text { Group IIb } \\
\text { (Stage-II) } \\
\mathrm{n}=30\end{array}$ & $\begin{array}{c}\text { Group IIc } \\
\text { (Stage-III) } \\
\mathrm{n}=30\end{array}$ & $\begin{array}{c}\text { Group IId } \\
\text { (Stage-IV) } \\
\mathrm{n}=30\end{array}$ \\
\hline Parameter & & & & & \\
\hline Age (years) & $48.3 \pm 9.7$ & $50.1 \pm 12.4$ & $49.3 \pm 9.9$ & $48.9 \pm 10.2$ & $50.3 \pm 11.1$ \\
\hline $\mathrm{P}$ & & $>0.05$ & $>0.05$ & $>0.05$ & $>0.05$ \\
\hline BMI (kg/m2) & $31.5 \pm 6.1$ & $30.4 \pm 7.6$ & $30.8 \pm 6.6$ & $31.3 \pm 6.4$ & $29.2 \pm 11.4$ \\
\hline $\mathrm{P}$ & & $>0.05$ & $>0.05$ & $>0.05$ & $>0.05$ \\
\hline
\end{tabular}

Invasive canal carcinoma (IDC) was the most prevalent histolopathological type of BC (99 cases; 82.5 per cent). There were 9 cases (7.5 percent) of invasive lobular carcinoma (ILC), 4 cases (3.34 percent) of mucinoma, 3 cases ( 2.5 percent) of medullary carcinoma, 3 cases ( 2.5 percent) of tumor with malignant phyllodes and 2 cases (1.66 percent) with improperly differentiated carcinoma. As with the classification of the tumour, 12 patients were of grade I (10\%), 79 patients were of grade II (65.8\%) and 29 patients were of grade III $(24.2 \%)$.

Nottingham Prognostic Index (NPI) (table 2)

Table 2: The breast cancer patients prognosis according to the NPI values.

\begin{tabular}{|l|l|l|}
\hline Patients prognosis according to NPI & $\mathrm{n}$ & Percentage \\
\hline - Excellent prognosis. & 2 & $1.67 \%$ \\
\hline - Good prognosis. & 19 & $15.83 \%$ \\
\hline - Moderate prognosis. & 75 & $62.5 \%$ \\
\hline - Poor prognosis. & 24 & $20 \%$ \\
\hline * Total & 120 & $100 \%$ \\
\hline
\end{tabular}


According to the NPI values that using three pathological criteria: the size of the tumour; the number of involved lymph nodes; and the grade of the tumour, out of 120 cases, 2 (1.67\%) were of excellent prognosis, 19 (15.83\%) were of good prognosis, 75 (62.5\%) were of moderate prognosis, while 24 $(20 \%)$ were of poor prognosis.

Serum stage CEA and CA 15-3

Gradual increase in serum CA 15-3 and CEA levels as the progress of the patient stage is evident (table $3)$.

Table 3: the mean values of CA15-3 and CEA in the groups of the study.

\begin{tabular}{|l|l|l|l|l|l|}
\hline Mean \pm SD & Control & Stage-I & Stage-II & Stage-III & Stage-IV \\
\hline \hline CEA $(\mathrm{ng} / \mathrm{mL})$ & $4.5+1.4$ & $6.5+5.7$ & $6.9+6.7$ & $6.8+5.2$ & $11.5+6.4$ \\
\hline P & & $<0.01$ & $>0.05$ & $>0.05$ & $<0.01$ \\
\hline CA 15-3(U/mL) & $12.4+7.8$ & $18.4+10.9$ & $19.6+11.7$ & $21.5+11.9$ & $24.4+8.9$ \\
\hline P & & $<0.01$ & $>0.05$ & $<0.05$ & $<0.01$ \\
\hline
\end{tabular}

Pearson correlation testing of the CEA and CA 15-3 serum with the patient's clinicopathological characteristics is shown in Table 4 and Figures 1,2, $3 \& 4$ showing a significant correlation between CEA levels and tumor size; Node rank, histopathological grade and NPI values and non-significant association with patient age, while CA15-3 demonstrated substantial correlation with histopathological grade and NPI values, and no meaningful correlation with age, tumor size or node position.

Table 4: Correlations between the of CEA and CA 15-3 and different clinic-pathological parameters in the breast cancer patients.

\begin{tabular}{|l|l|l|l|l|}
\hline \multirow{2}{*}{ Variables } & \multicolumn{2}{|l|}{ CEA } & \multicolumn{2}{l|}{ CA 15-3 } \\
\cline { 2 - 5 } & $\mathrm{r}$ & $\mathrm{p}$ & $\mathrm{r}$ & $\mathrm{p}$ \\
\hline Age & 0.02 & $>0.05$ & 0.02 & $>0.05$ \\
\hline Tumor size & 0.25 & $<0.05$ & 0.25 & $<0.05$ \\
\hline Node status & 0.23 & $<0.05$ & 0.23 & $<0.05$ \\
\hline Tumor grade & 0.2 & $<0.05$ & 0.2 & $<0.05$ \\
\hline NPI values & 0.26 & $<0.05$ & 0.26 & $<0.05$ \\
\hline
\end{tabular}




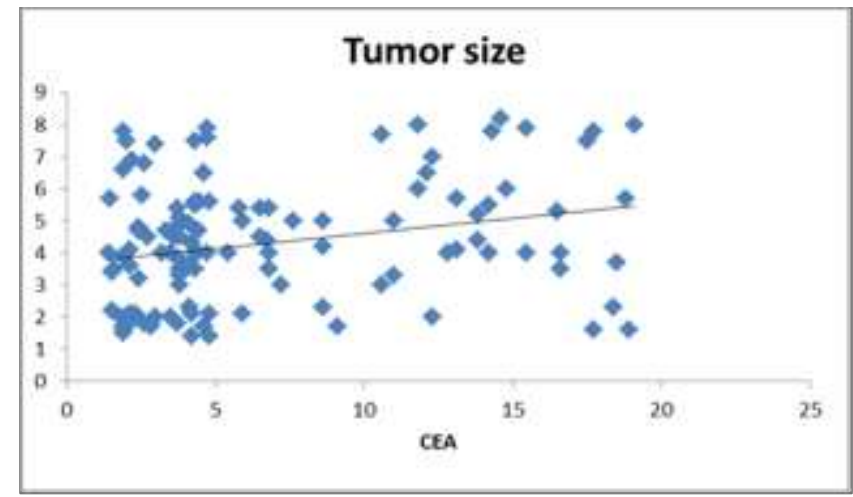

Figure 1: serum CEA is significantly correlated to the tumor size.

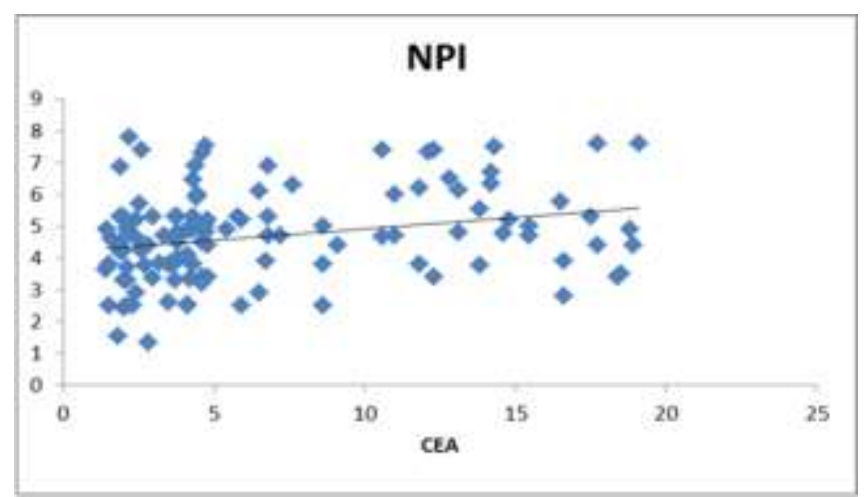

Figure 2: serum CEA is significantly correlated to the NPI.

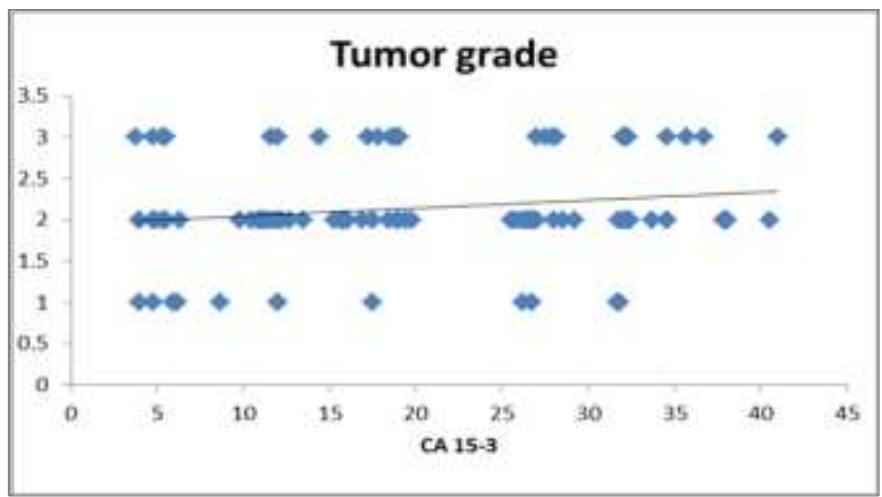

Figure 3: serum CA 15-3 is significantly correlated to the tumor grade.

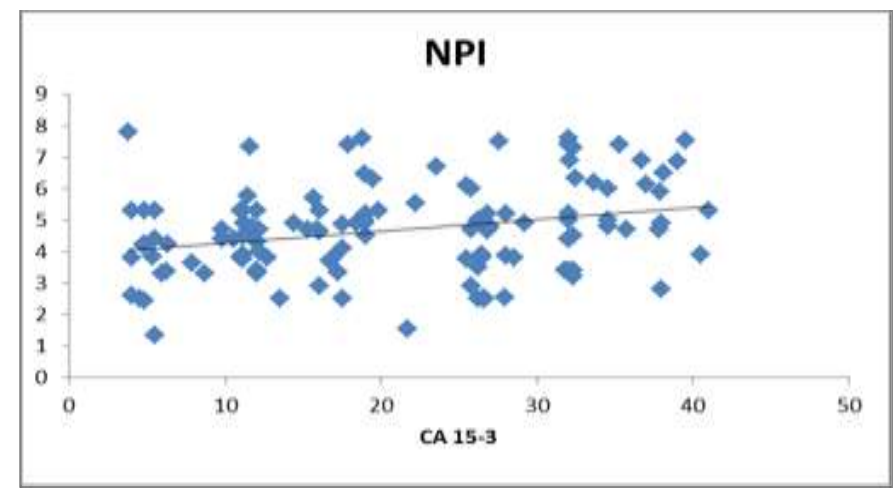

Figure 4: serum CA $15-3$ is significantly correlated to the NPI 
In terms of its etiology and pathological features, breast cancer is extremely heterogeneous, with certain patients exhibiting sluggish development and good prognosis, whereas other patients follow a more destructive clinical route. Huge research, economic and organizational initiatives are under way to identify the triggers of the initiation, Identify critical molecular progression players, and define new lines of intervention that provide greater benefits and less toxicity[ ' '].

As expected, breast cancer early diagnosis, either de-novo occurrence or recurrence, is a mainstay for planning of the management protocol, with the early tumor stages are most likely to give the patients the benefit of the adjuvant therapy [1 $\left.{ }^{r}\right]$. This study aimed to assess the importance of the CA15-3 and CEA levels in the breast cancer diagnosis and prognosis in Egyptian females.

There are controversial talking about the value of measuring CA15-3 and CEA serum in patients with breast cancer. One of the supporting organization for their in the diagnosis, prognosis and follow up of the treatment outcomes is the European Tumor Markers Community $1 r$ ]. However, others did not conclude beneficial roles of such biomarkers in the disease course diagnosis or prognosis [ 1 ₹]. This controversy could be partially secondary to conflicting results of various studies. The study of $\mathrm{Wu}$ et.al reported increased CA15-3 and CEA levels in $12.3 \%$ and $7.2 \%$ of patients with breast cancer, respectively [1 ${ }^{\circ}$ ]. In this study, we reported increased serum levels of CA15-3 and CEA in 48 (40\%) and 55 (46.8\%) patients, respectively. However, as we added all markers together, such percentage decreases when each were elevated in 74 patients $(61.7 \%)$.

\section{CONCLUSION}

Previous study showed that serum levels of CA15-3 and CEA were significantly the prognostic factors of tumor progression as the size of the tumor and the status of lymph nodes affection [17], slightly increased serum levels of CA15-3 and CEA were shown in the stage III breast cancer (locally advanced) [1 $\mathrm{\vee}]$. The present research also found that the serum CEA rates interacted favorably with the tumor scale, Node position, NPI rating, and tumor score. The node rank, tumor size, and NPI value were all positively associated with the serum levels of CA 15-3.

A documented association between higher serum levels of CA 15-3 and CEA and increased tumor load, with the more the increase in these biomarkers, the more risk for systemic metastasis. This result was confirmed by Lee et al research. They show also more frequent recurrence rate in patients with preoperative higher levels of these biomarkers [1^]. Since described biomarkers measuring is fairly simple, easy, cheap and little invasive method, it could be valuable screening method to depict the tumor recurrence as early as possible [19]. This study showed that the higher levels of both markers were in Stage IV (metastatic) group, and the poorest prognosis one.

\section{REFERENCES}

[1] ABDEL-AZIZ T, AZAB N, EMARA N, ODAH M AND I.M. EL-DEEN: Study of BRCA2 Gene Mutations in Egyptian Females with Breast Cancer. International Journal of Innovative Research in Science. 4(2): 283-288; 2015.

[2] SAUNDERS, CHRISTOBEL AND SUNIL: Breast cancer, Oxford University Press,2009, Chapter 13. 978 ISBN.

[3] KILPATRICK ES AND LIND MJ: Appropriate requesting of serum tumour markers, BMJ.339;3111; 2009.

[4] AMAYO A AND KURIA G: CLINICAL APPLICATION OF TUMOUR MARKERS: a review East African Medical Journal - African Journals. 86(12):76-83; 2009. 
[5] GAN N, JIA L, ZHENG L: A sandwich electrochemical immunosensor using magnetic DNA nanoprobes for carcinoembryonic antigen. International Journal of Molecular Sciences. 12 (11): 7410-23; 2011.

[6] DUFFY MJ: Carcinoembryonic antigen as a marker for colorectal cancer: is it clinically useful?". Clinical Chemistry. 47 (4): 624-30; 2001.

[7] BAHRAMI-AHMADI A, MAKARIAN F, MORTAZAVIZADEH M, YAZDI M AND CHAMANI M: Symptomatic metastasis prediction with serial measurements of CA 15.3 in primary breast cancer patients. J Res Med Sci. 17 (9): 850-854; 2012.

[8] SHAO X, SUN X, HE Y, LIU C AND LIU H: Elevated levels of serum tumor markers CEA and CA15-3 are prognostic parameters for different molecular subtypes of breast cancer. PLoS One. 10 (7): $\mathrm{e} 0133830 ; 2015$.

[9] MAHFOUZ AL-BACHIR AND MOHAMAD ADEL BAKIR. Predictive value of body mass index to metabolic syndrome risk factors in Syrian adolescents J Med Case Rep.; 11:1, $r \cdot \mid \mathrm{V}$.

[10] BEARZ, A. ET AL. MUC-1 (CA 15-3 antigen) as a highly reliable predictor of response to EGFR inhibitors in patients with bronchioloalveolar carcinoma: an experience on 26 patients. Int. J. Biol. Markers 22(4):307-311, 2007.

[11] GARNER J: "In the case of breast cancer, how can these be combined to give prognostic information?". Questions for the MRCS vivas. London: Arnold. p. 231; 2004.

[12] BALDASSARRE G AND BELLETTI B: Molecular biology of breast tumors and prognosis. F1000 Research journal. 13(1):5-9; 2016.

[13] SHAH K. ROSSO D AND NATHANSON P: Pathogenesis, prevention, diagnosis and treatment of breast cancer, World Journal of Clinical Oncology. 5(3):283-298; 2014.

[14] MOLINA R, BARAK V, VAN DALEN A, DUFFY MJ, EINARSSON R AND GION M: Tumor markers in breast cancer- European Group on Tumor Markers recommendations. Tumour Biol. 26:281-293; 2005.

[15] HARRIS L, FRITSCHE H, MENNEL R, NORTON L, RAVDIN P AND TAUBE S: American Society of Clinical Oncology 2007 update of recommendations for the use of tumor markers in breast cancer. J Clin Oncol. 25:5287-5312; 2007.

[16] WU S, HE Z AND ZHOU J: Serum levels of CEA and CA15-3 in different molecular subtypes and prognostic value in Chinese breast cancer. Breast. 23 (1): 88-93; 2014.

[17] PARK BW, OH JW, KIM JH, PARK SH, KIM KS AND LEE KS: Preoperative CA 15-3 and CEA serum levels as predictor for breast cancer outcomes. Ann Oncol. 19:675-681; 2008.

[18] HASHIM ZM: The significance of CA15-3 in breast cancer patients and its relationship to HER-2 receptor status. Int J Immunopathol Pharmacol. 27:45-51; 2014.

[19] LEE JS, PARK S, PARK JM, CHO JH, KIM SI AND PARK BW: Elevated levels of serum tumor markers CA 15-3 and CEA are prognostic factors for diagnosis of metastatic breast cancers. Breast Cancer Res Treat. 141:477-484; 2013.

[20] DI GIOIA D, HEINEMANN V, NAGEL D, UNTCH M, KAHLERT S AND BAUERFEIND I: Kinetics of CEA and CA15-3 correlate with treatment response in patients undergoing chemotherapy for metastatic breast cancer (MBC). Tumour Biol. 32:777-785; 2011. 